Www.jmscr.igmpublication.org

Impact Factor (SJIF): 6.379

Index Copernicus Value: 79.54

ISSN (e)-2347-176x ISSN (p) 2455-0450

crossrefDOI: https://dx.doi.org/10.18535/jmscr/v6i8.178

\title{
Prophylactic Efficiency of Oral Ephedrine in Preventing Hypotension Due to Spinal Anaesthesia for Caesarean Section
}

\author{
Authors \\ Ceena Panicker*, Parvathy.G \\ Department of Anaesthesiology, Medical College Hospital, Thiruvananthapuram, Kerala, India \\ *Corresponding Author \\ Ceena Panicker \\ Sandilands, Vidhya Nagar 4, Pattathanam, Kollam Kerala India 691021 \\ Email: ceenapanicker@gmail.com
}

\begin{abstract}
The commonest form of anaesthesia for caesarean section is spinal anaesthesia. It is associated with a fall in blood pressure with a comparable fall in uteroplacental blood flow. This leads to fetal hypoxia and acidosis. Baseline and intra operative heart rate and blood pressure were compared in sixty patients. The hemodynamic variables were noted in patients given oral ephedrine $30 \mathrm{mg}$ thirty minutes before subarachnoid block and patients given intravenous fluid preload alone. Statistically significant variation in heart rate and blood pressure were noted in the two groups. Lowest incidence of hypotension and change in heart rate was observed in the ephedrine group. The incidence of hypotension was less in the ephedrine group. No adverse effect of ephedrine was noted in the mother or fetus. Oral ephedrine is a simple and effective prophylactic measure to prevent hypotension due to spinal anaesthesia.
\end{abstract}

Keywords: Oral ephedrine, intravenous fluid, heart rate, blood pressure, hypotension.

\section{Introduction}

The commonest form of anaesthesia for caesarean section is spinal anaesthesia. The mortality with regional techniques caesarean section is less compared to general anaesthesia as depicted in the confidential enquiry into maternal deaths in U.K ${ }^{[1]}$.It provides a fast, profound, symmetrical sensory and motor block of high quality. The mother is awake and allows active maternal participation ${ }^{[2]}$. It also avoids problems of general anaesthesia like maternal aspiration, failed intubation and neonatal drug depression. It is safe, simple, rapidly administered and gives complete analgesia.
Ephedrine is the drug most often used to correct hypotension during spinal anaesthesia. Oral ephedrine is a simple and effective way of reducing incidence of hypotension in caesarean section under subarachnoid block ${ }^{[3]}$. Mild to moderate hypotension does not affect the mother but may have profound effects on uterine blood flow and fetal well being ${ }^{[4,5]}$. Hypotension can be prevented by various methods ${ }^{[6]}$. This includes left uterine displacement after block, slight Trendelenberg position to increase venous return, fluid preloading prior to block and vasopressors. The vasopressors used are mephentermine, metaraminol and ephedrine $^{[7,8]}$. Ephedrine has the most favourable 
effect on uterine blood flow and thus better neonatal outcome. It has been extensively studied by intramuscular and intravenous routes. Not many have been published on oral route ${ }^{[9,10,14]}$.

This study was undertaken to know whether oral ephedrine is effective in preventing hypotension due to spinal anaesthesia for caesarean section when given orally.

\section{Materials and Methods}

The hospital ethics committee approval was obtained. Only those participants willing to give informed consent were included in the study. Sixty ASA1, term, non laboring patients scheduled for elective caesarean section were included in the study. Patients with pregnancy induced hypertension, drug allergy, patients with contraindication for spinal anaesthesia and those with fetal anomalies were excluded from the study. Patients in ephedrine group receive $30 \mathrm{mg}$ ephedrine tablet orally 30-45 minutes before institution of subarachnoid block with sips of water and a fluid preload of $500 \mathrm{ml}$ normal saline. Fluid group receives a fluid preload alone. Heart rate and blood pressure were checked following administration of the drug.

Necessary investigations and a thorough preoperative evaluation were done. All patients were kept nil per orally for 8-10 hours. Aspiration prophylaxis was given with Ranitidine 50mg and Metoclopramide $10 \mathrm{mg}$ given orally the night before and morning of surgery. Basal heart rate and blood pressure were recorded prior to surgery with patient lying in left lateral position on 3 occasions, the average taken as baseline recording. Patients were placed in left lateral position. Lumbar subarachnoid block performed at L2-3 or L3-4 under strict asepsis. The time and level of block noted. Hypotension was defined as a decrease in systolic blood pressure $>20 \%$ from baseline or $<100 \mathrm{~mm}$ of $\mathrm{Hg}$. This was managed with mephentermine $6 \mathrm{mg}$ bolus, oxygen via mask and increasing rate of administration of intravenous fluid. Degree of fall in blood pressure and lowest blood pressure was noted down.
Statistical analysis was performed in $\mathrm{R}$ statistical software. Qualitative variables were described as mean or standard deviation or median with IQR depending on normality of the data. Qualitative variables were described in absolute values and percentages. Mean value of the 2 groups were compared with' $t$ ' tests. Median values described with MacWhitney ' $u$ ' test. Qualitative variables were compared with Chi square test.

\section{Results}

Sixty patients belonging to ASA grade 1 were studied. The median age was 26 (IQR.24.8-28). The median weight was 67(IQR63.2-72). The median height was 160(IQR158-162) as given in Table 1.

Table 1: Characteristics of Population studied

\begin{tabular}{|l|c|c|c|c|}
\hline & $\begin{array}{c}{[\mathrm{ALL}]} \\
\mathrm{N}=60\end{array}$ & $0 \mathrm{~N}=30$ & $1 \mathrm{~N}=30$ & p.overall \\
\hline Age. & $\begin{array}{c}26.0 \\
{[24.8 ; 28.0]}\end{array}$ & $\begin{array}{c}26.5 \\
{[24.2 ; 28.0]}\end{array}$ & $\begin{array}{c}26.0 \\
{[25.0 ; 28.0]}\end{array}$ & 0.917 \\
\hline Weight & 67.0 & 68.0 & 65.0 & 0.090 \\
{$[63.2 ; 72.0]$} & {$[66.0 ; 72.0]$} & {$[60.0 ; 69.8]$} & \\
\hline Height & 160 & 159 & 160 & 0.876 \\
{$[158 ; 162]$} & {$[158 ; 162]$} & {$[157 ; 162]$} & \\
\hline $\begin{array}{l}\text { Intial. } \\
\text { heart. } \\
\text { rate }\end{array}$ & 96.6 & 98.2 & 94.9 & 0.190 \\
\hline $\begin{array}{l}\text { Intial. } \\
\text { blood. } \\
\text { presure }\end{array}$ & $19.70)$ & $(10.8)$ & $(8.30)$ & \\
\hline
\end{tabular}

There was baseline comparability between the two groups. The spinal levels reached were T4 T5, T6. Mean of T4 was 8 (s.d 13.3\%).T5 was 22(s.d 36.7) and T6 was 30 (s.d 50\%) Out of the two groups studied, baby Apgar was 8 in 25 patients, out of which 15 were in group $1(50 \%)$ and 10 in group 2(33.3\%).Baby Apgar was 9 in 35 patients, out of which 15 were in group1(50\%) and 20 in group $2(66.7 \%)$ The median baby weight was 2.9 (IQR2.8$3.2)$. 
Table 2: Intraoperative data showing Level of block, Vasopressor use, Intravenous fluid

\begin{tabular}{|c|c|c|c|c|}
\hline & [ALL] N=60 & $0 \mathrm{~N}=30$ & $1 \mathrm{~N}=30$ & p.overall \\
\hline Spinal.level: & & & & 0.824 \\
\hline T4 & $8(13.3 \%)$ & $3(10.0 \%)$ & $5(16.7 \%)$ & \\
\hline T5 & $22(36.7 \%)$ & $11(36.7 \%)$ & $11(36.7 \%)$ & \\
\hline T6 & $30(50.0 \%)$ & $16(53.3 \%)$ & $14(46.7 \%)$ & \\
\hline Induction.delivery.time.Min. & $9.50[8.75 ; 11.0]$ & $10.0[9.00 ; 11.0]$ & $9.00[8.00 ; 10.0]$ & 0.259 \\
\hline Uterine.incision.time.Sec. & $70.0[60.0 ; 90.0]$ & $75.0[60.0 ; 90.0]$ & $70.0[60.0 ; 90.0]$ & 0.561 \\
\hline Mephenteramine.dose..mg & & & & $<0.001$ \\
\hline 0 & $33(55.0 \%)$ & $3(10.0 \%)$ & $30(100 \%)$ & \\
\hline 6 & $13(21.7 \%)$ & $13(43.3 \%)$ & $0(0.00 \%)$ & \\
\hline 12 & $14(23.3 \%)$ & $14(46.7 \%)$ & $0(0.00 \%)$ & \\
\hline IV.fluid..ml. & $775[700 ; 1225]$ & $1250[1200 ; 1500]$ & $700[650 ; 700]$ & $<0.001$ \\
\hline Baby. Apgar: & & & & 0.295 \\
\hline 8 & $25(41.7 \%)$ & $15(50.0 \%)$ & $10(33.3 \%)$ & \\
\hline 9 & $35(58.3 \%)$ & $15(50.0 \%)$ & $20(66.7 \%)$ & \\
\hline Baby. Wt.Kg. & $2.90[2.80 ; 3.20]$ & $2.90[2.62 ; 3.20]$ & $2.90[2.80 ; 3.27]$ & 0.290 \\
\hline
\end{tabular}

Table 3 Intra operative Hemodynamic data

\begin{tabular}{|l|c|c|c|}
\hline & $\begin{array}{c}\text { Fluid } \\
(\mathbf{n = 3 0})\end{array}$ & $\begin{array}{c}\text { Ephedrine } \\
(\mathbf{n = 3 0})\end{array}$ & $\mathbf{p}$ value \\
\hline Hypotension & 21 & 1 & $\mathbf{0 . 0 0}$ \\
\hline Bradycardia & 6 & $\mathbf{0}$ & 0.009 \\
\hline Tachycardia & 22 & 27 & 0.286 \\
\hline Ectopics & $\mathbf{0}$ & 2 & 0.155 \\
\hline
\end{tabular}

Table 4 Hypotension

\begin{tabular}{|l|c|c|c|}
\hline Details & $\begin{array}{c}\text { Fluid } \\
\text { group }\end{array}$ & $\begin{array}{c}\text { Ephedrine } \\
\text { group }\end{array}$ & p value \\
\hline $\begin{array}{l}\text { Less than 20\% from } \\
\text { the baseline value }\end{array}$ & 21 & 1 & $\mathbf{0 . 0 0}$ \\
\hline $\begin{array}{l}\text { Less than 30\% from } \\
\text { the baseline value }\end{array}$ & 14 & $\mathbf{0}$ & $\mathbf{0 . 0 0}$ \\
\hline
\end{tabular}

The mean initial heart rate was 96.6 (s.d 9.7). The median initial blood pressure was 110 (IQR110120). There was a statistically significant difference between the 2 groups studied.(p value $<0)$. The mephentermine required to treat hypotension was 0 with a mean of 33.(s.d55\%).A dose of $6 \mathrm{mg}$ with a mean of $13(\mathrm{~s} . \mathrm{d} 21.7 \%), 12 \mathrm{mg}$ with a mean of 14(s.d23.3\%)Out of the 33,3 were in group $1(\mathrm{~s} . \mathrm{d} 10 \%)$ and 30 in group 2(s.d100\%). With $6 \mathrm{mg}$, out of a total of13, 13 were in group1 (s.d43.3\%) and 0 in group 2 .With $12 \mathrm{mg}$, out of 14,14 were in group 1(s.d 40.7\%) and 0 in group2.There was a statistically significant difference in mephentermine dose between the 2 groups $(\mathrm{p}<0.001)$ The median intravenous fluid required in the 2 groups was775ml(IQR 700-1225).which attained statistical significance. The median induction delivery time was $9.5 \mathrm{mts}$ (IQR8.75-11) which failed to attain statistical significance. The median uterine incision delivery time in the 2 groups was 70secs (6090 secs). Both failed to attain statistical significance.

\section{Discussion}

We conducted the study to compare the hemodynamic changes occurring in caesarean patients given spinal anaesthesia receiving oral ephedrine prior to block with those receiving only intravenous fluid preload. The number of episodes of severe hypotension was more in the fluid group. Also the amount of vasopressor used in ephedrine group was less compared to fluid group. Chan et al compared the efficacy of prophylactic ephedrine over fluid preload in prevention of maternal hypotension during spinal anaesthesia for caesarean section $^{[11]}$. Oral route is advantageous as it avoids painful injections. Also the effect lasts for 3-6 hours. The protective effect of ephedrine extends into the post operative period.

There was a statistically significant difference in the incidence of hypotension between the two groups. Peak incidence of hypotension occurred 4-6 minutes of intrathecal drug administration. Kafle et al have proved the efficacy of oral ephedrine in other surgeries but there have not been studies on its use for caesarean section ${ }^{[4]}$. The risk of hypotension for a woman who received ephedrine is less frequent to control group in accordance with study by Alison Mac Arhur ${ }^{[13]}$.The mechanism of ephedrine is by its direct and indirect sympathomimetic actions .Thus 
it increases cardiac output and peripheral vascular resistance. There is a relative sparing of utero placental vasculature from its vasoconstricting action. Hollmen et al have studied the effect of prophylactic ephedrine and regional anaesthesia on intervillous blood flow ${ }^{[12]}$. Fetal acidemia may be associated with regional anaesthesia for caesarean delivery. Babies born to hypotensive mothers not receiving prophylactic measures have worse blood gases than those born to mothers receiving ephedrine ${ }^{[15]}$.

Though the study showed statistically significant results, it did not evaluate the effect of prophylactic oral ephedrine on neonatal acid base status and neurobehavioral scores. Another drawback is the low sample size. Future studies may be planned on comparing oral, intramuscular and intravenous ephedrine on neonatal outcome.

\section{Conclusion}

In this study the prophylactic Oral Ephedrine in pregnant patients decreased the incidence of hypotension anf intravenous fluid needed after Spinal anaesthesia. Further studies are needed to optimize the route and dose.

\section{Acknowledgement}

We would like to thank Dr.Induprbha Yadev for his help in statistical analysis of data

\section{References}

1. Department of health .Report on confidential enquires into maternal deaths in the United Kingdom. Her Majesty's stationary office London,1994.

2. King SW, Rosen MA, Prophylactic ephedrine and hypotension associated with spinal anaesthesia for caesarean delivery. Int.J. obstretic anaesthesia 1998..7,18-22.

3. Vercauteran, Marcel P.M.D Ph.D, Coppejans Haffman Mertens Adrieansen. Prevention of hypotension by a single 5mg dose of ephedrine during small dose spinal anaesthesia in prehydrated caesarian delivery patients.
4. Kafle S.K, Mathe S.M. Prophylactic oral ephedrine reduces the incidence of hypotension after subarachnoid block. Canadian journal of anaesthesia, 1991-1995, vol41.No.11.

5. Anna Lee, Warwick. D, Ngan kee, Tony Gin, Prophylactic ephedrine prevents hypotension during spinal anaesthesia for caesarian section but does not improve neonatal outcome, a qualitative systemic review. Can. J. Anesth 2002/49.6/PP.588599.

6. G.Lyons. Anaesthesia and analgesia for caesarian section. In recent advances in anaesthesia and analgesia. Adams and Cashman, vol 19.Churchill Livingston.

7. David W Cooper,Mark Carpenter, Fetal and maternal effects of phenylephrine, and ephedrine using spinal anaesthesia for caesarian delivery. Anesthesiology, 2002.97, 1582.90.

8. Ngan kee W.D. Lau T.K, Khaw K.S Lee B.B, Anesthesiology 2001.95,307-13. Comparison of metaraminol and ephedrine infusion for maintaining arterial pressure during spinal anaesthesia for caesarian delivery.

9. Carvalho ICA Cardoso MMSC, Capette EL, Amaro AR, Rosa MCR prophylactic ephedrine during caesarian delivery spinal anaesthesia. Dose response study of bolus and continuous infusion Rev. Bras. Anesthesiol. 1999.49.309-14

10. J. Breckling, Ed., The Analysis of Directional Time Series: Applications to Wind Speed and Direction, ser.

11. S. Zhang, C. Zhu, J. K. O. Sin, and P. K. T. Mok, "A novel ultrathin elevated channel low-temperature poly-Si TFT," journal name., vol. 20, pp. 569-571, Nov. 1999.

12. Hollman AL, Joupilla R,Albright A et al. Intervillous blood flow during caesarean section with prophylactic ephedrine and epidural anaesthesia Acta Anesthesiol second 1984,28..396-400. 
13. Alison Mac Arthur. Canadian journal of anaesthesia 2002...vol 49,536-539.

14. Gutshe BB, Prophylactic ephedrine preceding spinal analgesia for caesarean section, Anaesthesiology 1976,45..462-5.

15. Johnson. Fetal acidemia associated with regional anaesthesia for elective caesarean delivery. Obstet. Gynecol 995,85..79-83. 